LAWRENCE LIVERMORE N A T IO N A L LABORATORY

Influence of the Environment on

the General Corrosion Rate of Alloy 22 (N06022)

R. B. Rebak, P. Crook

April 20, 2004

American Society of Mechanical Engineers Pressure Vessels and Piping

San Diego, CA, United States

July 25, 2004 through July 29, 2004 
This document was prepared as an account of work sponsored by an agency of the United States Government. Neither the United States Government nor the University of California nor any of their employees, makes any warranty, express or implied, or assumes any legal liability or responsibility for the accuracy, completeness, or usefulness of any information, apparatus, product, or process disclosed, or represents that its use would not infringe privately owned rights. Reference herein to any specific commercial product, process, or service by trade name, trademark, manufacturer, or otherwise, does not necessarily constitute or imply its endorsement, recommendation, or favoring by the United States Government or the University of California. The views and opinions of authors expressed herein do not necessarily state or reflect those of the United States Government or the University of California, and shall not be used for advertising or product endorsement purposes. 
18 April 2004

Paper to be presented at the American Society of Mechanical Engineers Pressure Vessels and Piping Division (ASME-PVP) Conference in San Diego, CA 25-29 July 2004

\title{
Influence of the Environment on the General Corrosion Rate of Alloy 22 (N06022)
}

\author{
Raúl B. Rebak and Paul Crook* \\ Lawrence Livermore National Laboratory, Livermore, CA 94550 \\ * Haynes International Inc., Kokomo, IN 46901
}

\begin{abstract}
Nickel (Ni) can dissolve a large amount of alloying elements while still maintaining its desirable austenitic microstructure. The resulting alloys are generally divided in families depending on the type of alloying elements they contain. Each one of these families is aimed to specific applications. Corrosive environments in industrial applications are generally divided for example in reducing acids, oxidizing acids, contaminated acids, caustic environments, oxidizing salts, etc. Depending on the application and the environment (electrolyte composition and temperature) several or single alloys may be recommended to fabricate components. The $\mathrm{Ni}$ chromium-molybdenum (Ni-Cr Mo) series contains a balanced selection of beneficial alloying elements so it can handle a variety of aggressive environments. By design, Alloy 22 or N06022 is one of the most versatile corrosion resistant nickel alloys since it has an outstanding corrosion resistance both in reducing and oxidizing conditions.
\end{abstract}

\section{INTRODUCTION}

Nickel alloys for corrosion applications can be divided intro five general families. The grouping is set by the main alloying elements the alloys contain. ${ }^{1}$ The families are: (1) Commercial pure nickel which includes Ni-200 (N02200), (2) Ni-Mo such as Alloy B-2 (N10665), (3) Ni-copper (Cu) such as Alloy 400 (N04400), (4) Ni-Cr Mo such as Alloy 22 (N06022) and (5) Ni-Cr-iron (Fe) such as Alloy 600 (N06600). This last family of alloys may also include a silicon ( $\mathrm{Si}$ ) containing alloy (D-205), which was designed for super oxidizing applications. All the Ni alloys mentioned above are austenitic (face centered cubic) in their annealed condition, that is, they possess great ductility and toughness. Each family is intended for specific applications where its alloys will perform better than any other alloy from the other families. For example, in caustic environments, such as in concentrated sodium hydroxide $(\mathrm{NaOH})$ at temperatures higher than $100^{\circ} \mathrm{C}, \mathrm{Ni}-200$ will perform far better than any of the higher alloyed materials. This is because in hot caustic conditions $\mathrm{Cr}, \mathrm{Mo}, \mathrm{Fe}$ and tungsten (W) may tend to dissolve preferentially from the alloys leaving behind a matrix of pure Ni (a dealloying process). ${ }^{2,3}$ Similarly, in hot hydrochloric acid $(\mathrm{HCl})$ solutions (highly reducing conditions) the best Ni alloy would B-2 or B-3 since these alloys contain the largest amount of Mo (approx. $28 \%$ ). Mo was shown to be one of the best alloying elements for protection against corrosion in hot reducing $\mathrm{HCl}$ solutions since it provides a low exchange current density for hydrogen evolution. $^{4}$

Alloy 22 belongs to the corrosion resistant family of Ni-Cr Mo alloys. The required composition and mechanical properties of this family are described in ASTM B575. ${ }^{5}$ The grandparent alloy of this family was the cast version of Alloy $\mathrm{C}$ first introduced in the market in 
the 1930s. ${ }^{6}$ In the 1960s, the wrought Alloy C-276 (N10276) was developed by basically eliminating the impurities of the cast Alloy C. Alloy C-276 contains approximately $16 \% \mathrm{Cr}, 16 \%$ Mo, 4\% W and some residual Fe (Table 1). Later, Alloys C-4 (N06455) and C-22 (N06022) appeared as modified versions of C-276. In the 1990s, Alloys 59 (N06059), C-2000 (N06200), MAT 21 (N06210) and Inconel 686 (N06686) were designed based on the good performance of Alloy 22, basically by increasing the amount of alloying elements such as Mo and Cr. Alloy 625 (N06625) can also be considered a member of the Ni-Cr Mo alloy family even though it has less Mo (approx. 9\%) (Table 1). Many times, Inconel 625 is preferred for high temperature applications rather than for aqueous solutions applications.

Alloy 22 (N06022) was first introduced in the market in the earlier 1980s. It was designed based on the concept of the atomic percent factor (APF), which reflects the opposing role of $\mathrm{Cr}$ to that of $\mathrm{Mo}$ and $\mathrm{W}$ in reducing and oxidizing acidic solutions. ${ }^{7,8} \mathrm{~A}$ reducing solution has a redox potential with a cathodic current controlled by hydrogen evolution reaction (HER) and an oxidizing solution has a redox potential controlled by a cathodic reaction with a potential higher than HER (e.g. $\mathrm{Fe}^{3+}$ or nitric acid). The APF was described as: 7,8

$$
A P F=\frac{4 C r}{(2 M o+W)}
$$

Where the symbols represent weight percentage of the element in the alloy. In oxidizing conditions such as ASTM G 28A, the higher the Cr content (i.e. the higher the APF) the lower the corrosion rate. In reducing conditions such as boiling hydrochloric acid, the higher the Mo and $\mathrm{W}$ contents (i.e. the lower the APF) the lower the corrosion rate. The ultimate versatility of an alloy that can be used both in oxidizing and reducing conditions would be a chemical composition that would yield a APF of 2.5 to 3.3. ${ }^{7}$ The APF of N06022 is 3.03.

The objective of this work was to document the corrosion performance of Alloy 22 and other engineering alloys in a variety of environments. The corrosion rates were obtained using immersion tests (ASTM G 31) ${ }^{9}$ and most of the data originated from Haynes International database. Only corrosion rates in environments that show uniform thinning of the alloys are shown. In other environments (not shown in this paper) such as caustic solutions or wet hydrofluoric acid (HF), the corrosion front or thinning may not progress uniformly. Some of this data has been published before.

\section{EFFECT OF TEMPERATURE AND ACID CONCENTRATION}

Figure 1 shows the corrosion rate of N06022 as a function of the concentration of hydrochloric acid $(\mathrm{HCl})$ for boiling solutions, that is, under highly reducing conditions. The corrosion rate of Alloy 22 increases more than three orders of magnitude as the acid concentration increases from $0.2 \%$ to $20 \%$. The largest change in corrosion rate occurs in the $\mathrm{HCl}$ concentration range between $1 \%$ and $3 \%$. Figure 2 shows the effect of the temperature on the corrosion rate of N06022 and other alloys of the same Ni-Cr Mo family (Table 1) in 50\% sulfuric acid. For all the alloys the corrosion rate starts to increase rapidly above $93^{\circ} \mathrm{C}$, following an Arrhenius type of relationship with the temperature. The effect of the temperature is similar for all the alloys in Figure 2. N06200 has the lowest corrosion rate in sulfuric acid, probably because besides its 16\% Mo, N06200 also has1.6\% of $\mathrm{Cu}$, a beneficial alloying element for sulfuric acid service. 


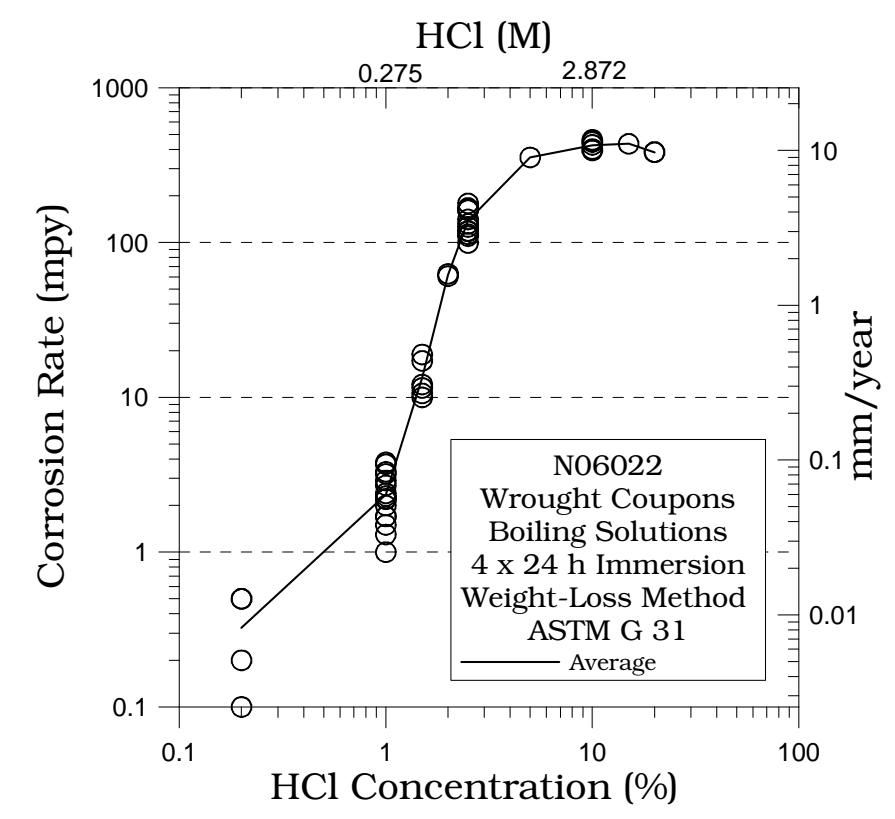

Figure 1. Corrosion Rate of N06022 in Boiling HCl Solutions.

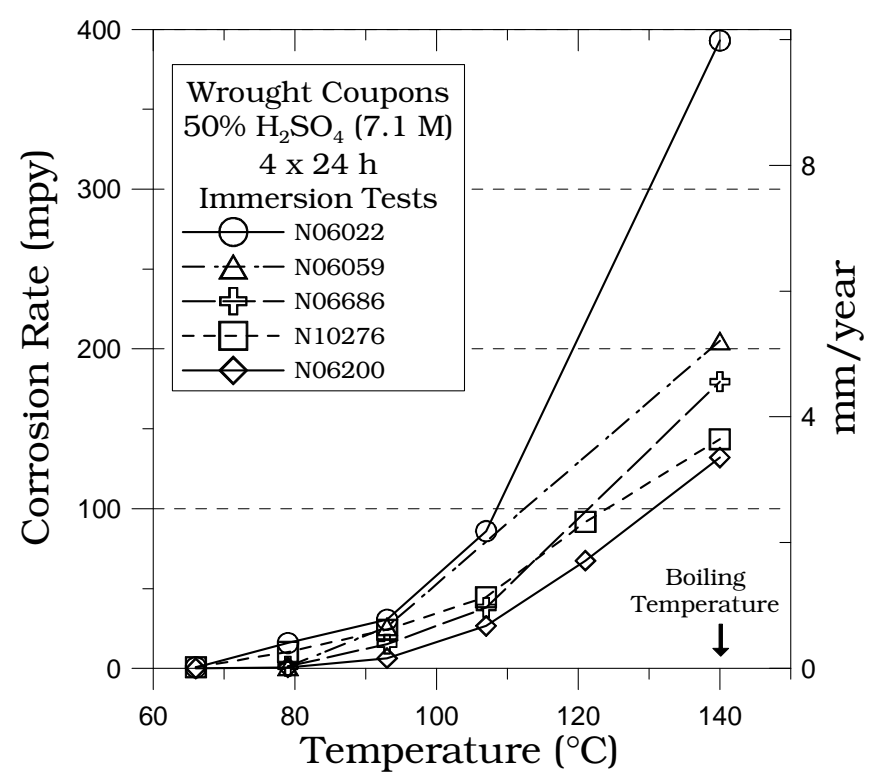

Figure 2. Corrosion Rate of Ni-Cr Mo Alloys in 50\% Sulfuric Acid Solution.

\section{CORROSION RATE IN OXIDIZING ENVIRONMENTS}

An environment can be considering oxidizing when the cathodic reaction is controlled by a reduction process that has a potential higher than the hydrogen evolution reaction potential. For example, an environment containing large amounts of dissolved oxygen or ferric ions $\left(\mathrm{Fe}^{3+}\right)$ can be considered oxidizing. Figure 3 shows the corrosion rate of Alloy 22 and other engineering alloys in the ASTM G 28B, which is a 24-h coupon immersion test in a boiling solution of $23 \%$ sulfuric acid $\left(\mathrm{H}_{2} \mathrm{SO}_{4}\right)$ plus $1.2 \% \mathrm{HCl}+1 \%$ ferric chloride $\left(\mathrm{FeCl}_{3}\right)+1 \%$ cupric chloride $\left(\mathrm{CuCl}_{2}\right)$. 


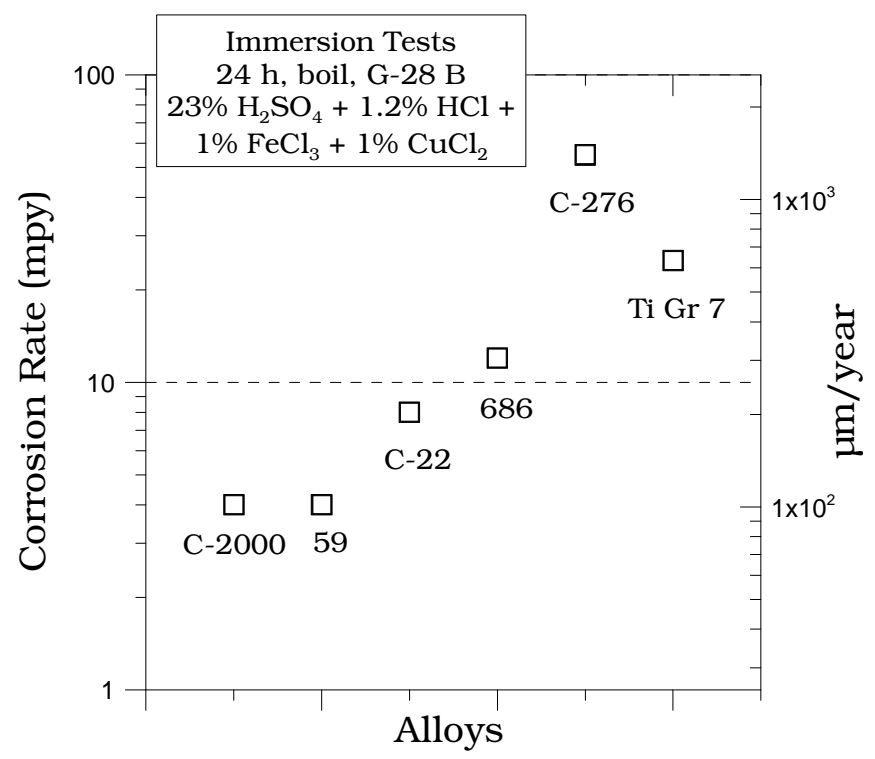

Figure 3. Corrosion Behavior of Engineering Alloys in ASTM G 28 B Solution.

ASTM G $28 \mathrm{~B}$ is a highly acidic (because of $\mathrm{HCl}+\mathrm{H}_{2} \mathrm{SO}_{4}$ ) and highly oxidizing (because opf $\mathrm{FeCl}_{3}+\mathrm{CuCl}_{2}$ ) solution, and also contains a large amount of chloride ions. ${ }^{9}$ This solution would induce pitting corrosion in Ni-Cr Fe alloys -not shown in Figure 3- such as Alloys 600, G3 or N06985 and 825 or N08825 and in austenitic stainless steels such as 316L SS (S31603) (Table 1). The highest corrosion rate in Figure 3 corresponds to $\mathrm{C}-276$, which has the lowest $\mathrm{Cr}$ content. The corrosion rate of Alloy 22 was comparable to that of the more recently developed Ni-Cr Mo alloys such as C-2000, 59 and 686. The lower corrosion rates of Alloys 59 and C-2000 could be because these alloys do not contain W.

Figure 4 shows corrosion rate data for Alloy 22 and other engineering alloys in plain oxidizing solutions without chloride ions. The ASTM G 28A standard (or Streicher test) refers to the immersion of the test coupons in a boiling solution of $50 \%$ sulfuric acid $\left(\mathrm{H}_{2} \mathrm{SO}_{4}\right)+42 \mathrm{~g} / \mathrm{L}$ ferric sulfate $\left(\mathrm{Fe}_{2}\left(\mathrm{SO}_{4}\right)_{3}\right)$ for $24 \mathrm{~h}$. The tests in the boiling solution of nitric acid $\left(\mathrm{HNO}_{3}\right)$ were carried out for four periods of $24 \mathrm{~h}$, changing the corroding solution at the end of each period.

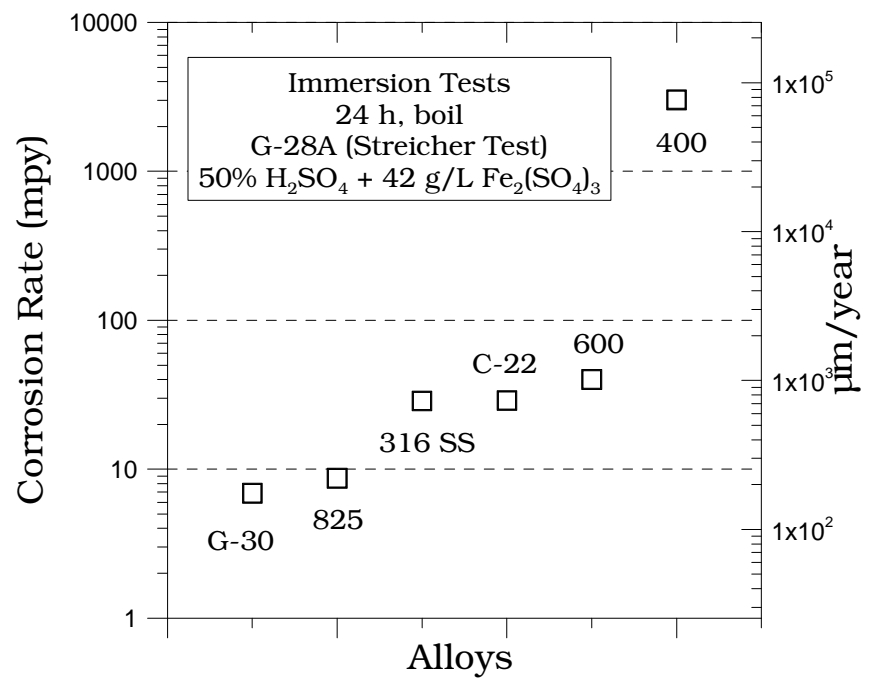




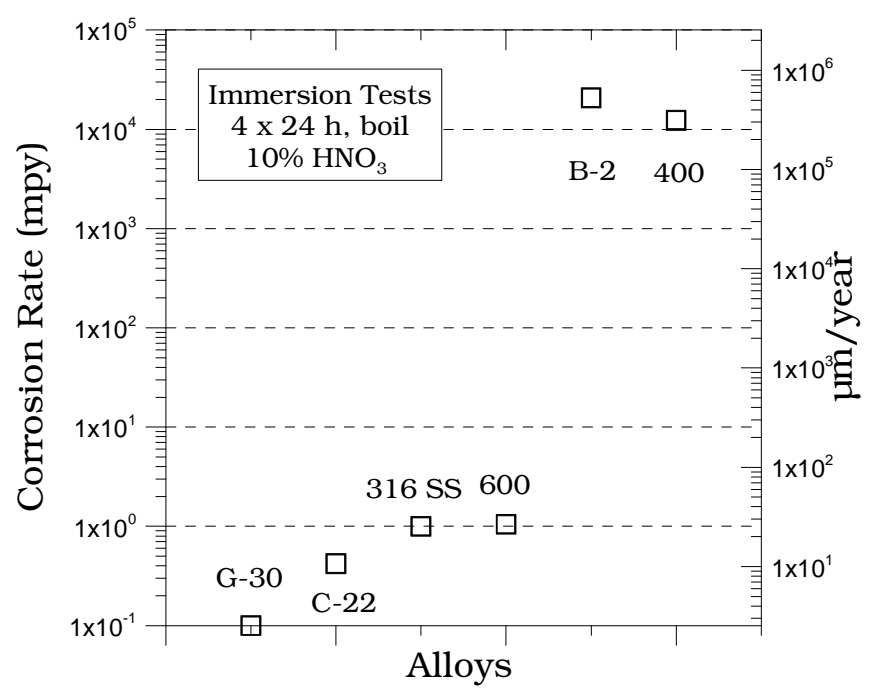

Figure 4. Corrosion Behavior of Engineering Alloys in ASTM G 28 A and $\mathrm{HNO}_{3}$ Solutions

The corrosion rate in oxidizing environments shown in Figure 4 seem to be controlled by the formation of a passivating Cr-rich oxide film on the metal surface In ASTM G 28A, the corrosion rates of Alloys G-30 (N06030) and 825 (both Ni-Cr Fe alloys) were lower than that of Alloy 22. For example, the high concentration of $\mathrm{Cr}(30 \%)$ in $\mathrm{G}-30$ added to the $15 \%$ Fe develop a protective oxide film which reduced the corrosion rate of these materials. Moreover, G-30 and 825 have low concentration of Mo, which may be attractive for pure oxidizing solutions. The corrosion rate of $316 \mathrm{SS}$ was comparable to that of Alloy 22. Non-passivating alloys such as Ni$\mathrm{Cu}$ Alloy 400 have high corrosion rates in ASTM G 28A (Figure 4).

In boiling nitric acid, the corrosion rate of non-passivating alloys such as B-2 and 400 was several orders of magnitude higher than the corrosion rate of $\mathrm{Ni}$ alloys containing at least $16 \% \mathrm{Cr}$ (such as Alloy 600). Similarly as in ASTM G 28A, the corrosion rate of Alloy 22 in boiling 10\% $\mathrm{HNO}_{3}$ was comparable to that of G-30. In general, the corrosion rate of all engineering materials in Figure 4 is lower in $10 \% \mathrm{HNO}_{3}$ than in ASTM G 28A.

\section{CORROSION RATE IN REDUCING ENVIRONMENTS}

Figure 5 shows the corrosion rates for Alloy 22 and other engineering alloys in boiling solutions of reducing acids. These solutions are termed reducing because the amount of dissolved oxygen is low and because the cathodic reaction is controlled by the hydrogen reduction reaction. The corrosion rate of each material is shown for $10 \% \mathrm{HCl}$ and $10 \% \mathrm{H}_{2} \mathrm{SO}_{4}$ solutions. The concentration of protons in each solution would be similar since the second dissociation of $\mathrm{H}_{2} \mathrm{SO}_{4}$ is weak. The first observation from Figure 5 is that each material has a higher corrosion rate in the $\mathrm{HCl}$ solution than in the $\mathrm{H}_{2} \mathrm{SO}_{4}$ solution, especially in alloys containing chromium (e.g. Alloy 600). That is, Cr seems to be a beneficial alloying element in sulfuric acid solutions. $\mathrm{Cu}$ is also a beneficial alloying element for $\mathrm{H}_{2} \mathrm{SO}_{4}$ service explaining the low corrosion rate of Alloy G-30. In general, for these two solutions, the higher the Mo content in the alloy the lower the corrosion rate. That is, alloys such as B-2 (N10665) and C-276 have lower corrosion rates than Alloy 22 since they contain higher amounts of Mo. In $\mathrm{H}_{2} \mathrm{SO}_{4}$ the corrosion rate of Alloy 22 is slightly lower than that of C-276 probably because the higher $\mathrm{Cr}$ content in the former compensates for the higher Mo content in the latter. Alloys with less than $10 \%$ Mo and also containing more than $10 \% \mathrm{Fe}$ (G-30, 600 and $316 \mathrm{SS}$ ) offer a high corrosion rate in the $\mathrm{HCl}$ 
solution. Results from Figure 5 explains why a designer will choose B-2 over Alloy 22 to fabricate a centrifuge that needs to operate in a hot $\mathrm{HCl}$ solution.

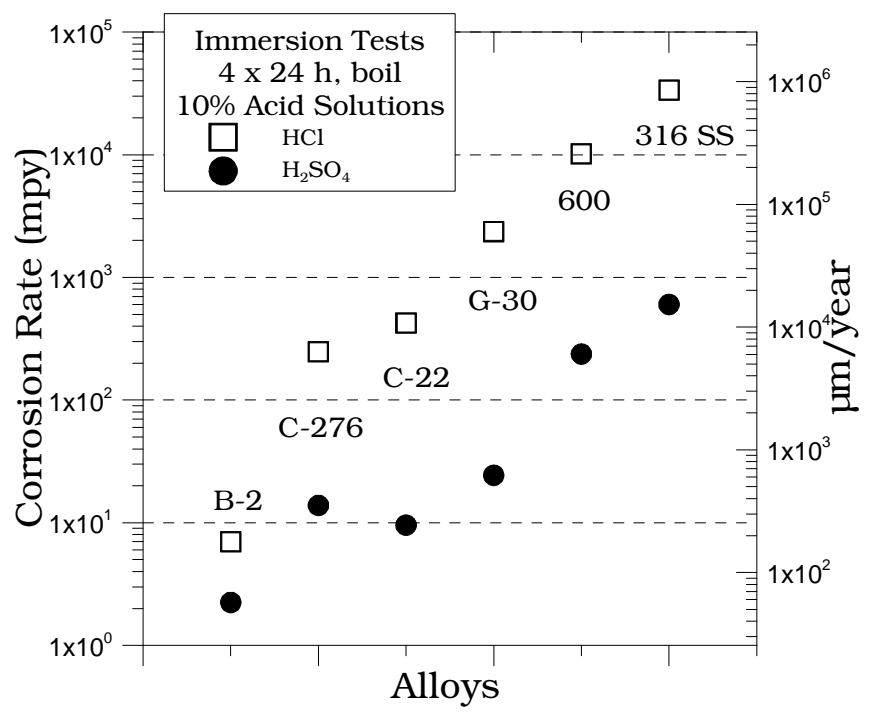

Figure 5. Corrosion Behavior of Engineering Alloys in Acidic Reducing Solutions.

\section{RANGE OF CORROSION RATES}

Figure 6 shows the corrosion rate for Alloy 22 in a variety of environments. It is apparent, just with a few examples that the corrosion rate of Alloy 22 can be changed by several orders of magnitude (from $10^{-5}$ to $10 \mathrm{~mm} /$ year) just by changing the conditions of the environment acting on the alloy. These environmental changes include for example solution composition, temperature and redox potential. The lowest corrosion rate in Figure 6 (20 nm/year) was obtained by weight loss after testing for more than five years in simulated concentrated ground waters at 60 and $90^{\circ} \mathrm{C} .{ }^{11}$ The highest corrosion rate of $12 \mathrm{~mm} /$ year was obtained by immersion testing of Alloy 22 in boiling $10 \% \mathrm{HCl}$ for $96 \mathrm{~h}$ (Figure 6).

Alloy 22 was especially designed to give an outstanding corrosion performance in a wide range of (acidic) environments from reducing to oxidizing. Only a few possible environmental conditions were presented in this work to illustrate the comparative behavior of Alloy 22 with other engineering alloys. Alloy 22 may not have the lowest corrosion rate in all possible environments; however, data shows that Alloy 22 has the right amount of beneficial elements to make it versatile so it can be used in a variety of applications, from reducing to oxidizing, from acidic to alkaline. $\mathrm{Ni}$ is the element that protects against corrosion in caustic solutions, $\mathrm{Cr}$ protects against oxidizing acidic conditions and Mo $(+\mathrm{W})$ protects against acidic reducing conditions. Figure 4 shows the corrosion rate for Alloy 22 in a variety of environments. 


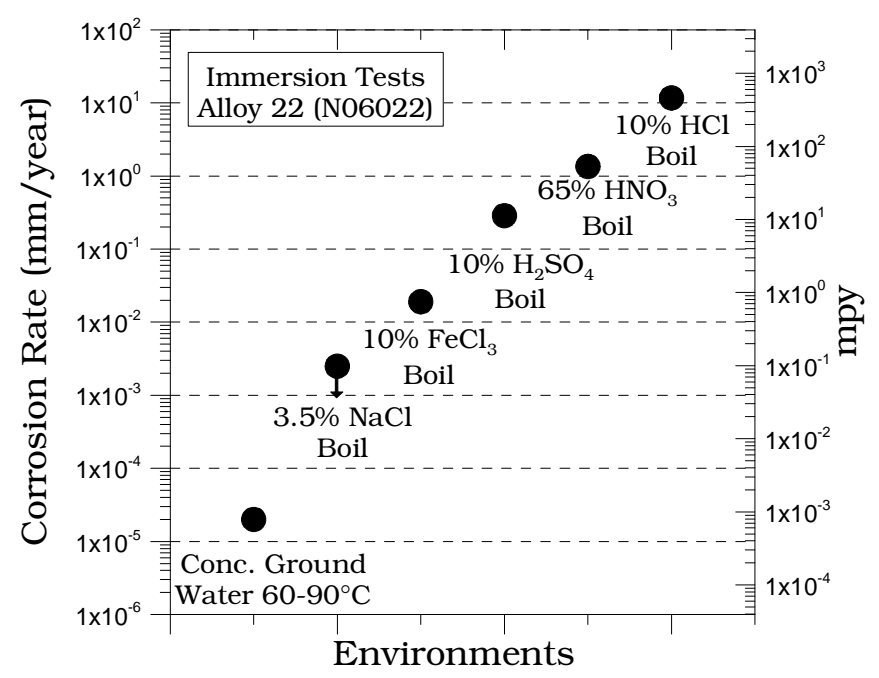

Figure 6. Ranges in the Corrosion Rate of Alloy 22.

\section{CONCLUSIONS}

1. Alloy 22 or N06022 was designed to operate in a wide range of environments from reducing to oxidizing

2. Ni protects N06022 in caustic conditions, $\mathrm{Cr}$ in oxidizing acids and Mo in reducing acids

3. The corrosion rate of Alloy 22 can be changed by several orders of magnitude by changing the environmental conditions such as solution composition, temperature and redox potential.

\section{ACKNOWLEDGMENTS}

This work was partially performed under the auspices of the U. S. Department of Energy by the University of California Lawrence Livermore National Laboratory under contract $\mathrm{N}^{\circ}$ W-7405Eng-48. The work was supported by the Yucca Mountain Project, which is part of the DOE Office of Civilian Radioactive Waste Management (OCRWM) 


\section{REFERENCES}

1 R. B. Rebak, "Corrosion of Non-Ferrous Alloys. Nickel, Cobalt, Copper, Zirconium and Titanium Based Alloys," in Corrosion and Environmental Degradation, Volume II, p. 69-111 (Wiley-VCH, 2000: Weinheim, Germany).

2 R. B. Rebak and G. B. Chambers "Corrosion Behavior of Nickel Alloys in Caustic Solutions" Materials Solutions 2001, Indianapolis 5-8 November 2001, p. 26 (ASM International, 2001: Metals Park, $\mathrm{OH})$.

3 G. B. Chambers and N. S. Meck "Caustic Dealloying Corrosion" Stainless Steel World Conference, Houston 12-14 February 2002, P0228, p. 238-240 (KCI Publishing).

4 E. A. Lizlovs and A. P. Bond, J. Electrochem. Soc., 118, 22 (1971).

5 ASTM International, "Standard Specification for Low-Carbon Nickel-Molybdenum-Chromium, LowCarbon Nickel-Chromium-Molybdenum, Low-Carbon Nickel-Chromium-Molybdenum-Copper, Low-Carbon Nickel-Chromium-Molybdenum-Tantalum and Low-Carbon Nickel-ChromiumMolybdenum-Tungsten Alloy Plate, Sheet and Strip", Standard B575, Volume 02.04 (ASTM, 2002: West Conshohocken, PA).

6 D. C. Agarwal, "Nickel and Nickel Alloys" Uhlig's Corrosion Handbook, p. 831-851 (John Wiley and Sons, 2000: New York, NY).

7 A. Asphanhani, P. E. Manning and J. Straatmann "New Advances in Molybdenum-Containing Corrosion Resistant Alloys", J. of Molybdenum Technology, 10, 1, 1 (1987).

8 N. Sridhar, J. B. C. Wu and P. E. Manning "Corrosion Resistant Ni-Cr-Mo Alloys", J. of Metals, 37, 11, 51 (1985).

9 ASTM International, Volume 03.02, Standards G 28 "Standard Test Methods of Detecting Susceptibility to Intergranular Corrosion in Wrought, Nickel-Rich Chromium-Bearing Alloys" and G 31 "Standard Practice for Laboratory Immersion Corrosion Testing of Metals" Specification for Laboratory Testing" (ASTM International, 2003: West Conshohocken, PA).

10 R. B. Rebak and P. Crook, "Nickel Alloys for Corrosive Environments, Advanced Materials and Processes, 157, February 2000, pp. 37-42.

11 L. L. Wong, D. V. Fix, J. C. Estill, R. D. McCright and R. B. Rebak, "Characterization of the Corrosion Behavior of Alloy 22 after Five Years Immersion in Multi-Ionic Solutions," Vol. 757, p 735-741 (Materials Research Society, 2003: Warrendale, PA).

Table 1. Approximate Chemical Composition (in wt \%) of Alloys of Interest Alloys are listed in alphabetical order by UNS number

\begin{tabular}{|c|c|c|c|c|c|c|}
\hline Alloy & $\mathrm{Ni}$ & $\mathrm{Cr}$ & $\mathrm{Mo}$ & $\mathrm{W}$ & $\mathrm{Fe}$ & Other \\
\hline $\mathrm{N} 04400$ & 67 & & & & $2.5^{*}$ & $31 \mathrm{Cu}$ \\
\hline $\mathrm{N} 06022$ & 57 & 22 & 13 & 3 & 3 & $2.5 \mathrm{Co}^{*}, 0.35 \mathrm{~V}^{*}$ \\
\hline $\mathrm{N} 06030$ & 43 & 30 & 5.5 & 2.5 & 15 & $2 \mathrm{Cu}, 5 \mathrm{Co}^{*}, 1.5 \mathrm{Nb}^{*}$ \\
\hline $\mathrm{N} 06059$ & 60 & 23 & 16 & & $<1$ & \\
\hline $\mathrm{N} 06200$ & 59 & 23 & 16 & & & $1.6 \mathrm{Cu}$ \\
\hline $\mathrm{N} 06455$ & 65 & 16 & 16 & & $3 \mathrm{Fe}^{*}$ & $0.7 \mathrm{Ti}, 2 \mathrm{Co}^{*}$ \\
\hline $\mathrm{N} 06600$ & 75 & 16 & 9 & & & 5 \\
\hline $\mathrm{N} 06686$ & 46 & 21 & 16 & 4 & 5 & $2 \mathrm{Cu}^{*} 1 \mathrm{Ti}$ \\
\hline $\mathrm{N} 08825$ & 42 & 22 & 3 & & 31 & $2.5 \mathrm{Co}^{*}, 0.35 \mathrm{~V}^{*}$ \\
\hline $\mathrm{N} 10276$ & 57 & 16 & 16 & 4 & 5 & $2 \mathrm{Mn}^{*}$ \\
\hline $\mathrm{N} 10665$ & 69 & 0.5 & 28 & & 1.5 & \\
\hline $\mathrm{S} 31600$ & 12 & 17 & 2.5 & & 67 & \\
\hline
\end{tabular}

